The lunatic "will be a burthen on the nation as long as he lives." No doubt of the fact. It is indeed lamentable that the heavily taxed ratepayers should have to support in chronic idleness so many dangerous as well as harmless lunatics, and that the State should have to contribute towards the maintenance of the man who so suddenly deprived the country of the valuable services of an upright and useful public servant. Can Mr. Coates suggest a remedy for these admitted grievances apart from acting on the lex talionis principle? Mr. Coates says that the death of Mr. Lutwidge by an act of murderous violence must be considered as "a happy termination of a useful and honourable career." "Happy termination" indeed! In what does Mr. Lutwidge's happiness consist, apart altogether from his being the recipient of the rewards which no doubt will be meted to him for having lived a "sober, godly, and righteous life"? Death, under its most favourable aspects, is a solemn and awful event; but how terribly appalling it is to our every sense when one so highly respected by all who knew him is suddenly struck down by the hands of an assassin (whose interests he was in the act of promoting) be he sane or insane, responsible or irresponsible.

I am, Sir, your obedient servant,

Forbes WINSLOW, M.D.

Cavendish-square, June 14th, 1873.

\section{THE COLLEGE OF SURGEONS' ELECTION.}

\section{To the Editor of THE LANCET.}

Sir, - I have ever taken a lively interest in the election of Fellows to serve as members of the Council of the Royal College of Surgeons.

Mr. Thomas Wakley, having been nominated as a candidate for the membership of the Council, I have been at some unusual pains to ascertain his medico-political views, and I find them to be as follows:-

1. The proceedings of the Council should be published.

2. The representation of the College in the General Medical Council should be vested in the suffrages of the fellows and members of the College.

3. The examiners should be elected from the body of the profession, and not be (exclusively?) members of the Couneil. They should hold office for two or three years, and be eligible once only for re-election.

4. Fellows residing at a certain distance from the College should be allowed to vote by proxy.

5. Presidents and vice-presidents should be chosen from the members of the Council generally, and not from the examiners only.

6. Successive re-election of retiring councillors is highly objectionable.

7. A proportionate number of provincial surgeons should always be chosen to serve upon the Council.

8. Meetings of members and fellows within the walls of the College should be permitted under certain conditions.

Mr. Wakley is a proprietor of The LANCET. Having been exclusively engaged in the practice of his profession, he has never taken the slightest part in the editorial conduct of that journal.

The medico-political school in which Mr. Wakley has been brought up should not be forgotten. His father, the late Mr. Wakley, half a century ago inaugurated, and to the close of his career consistently and indefatigably promoted, those very reforms in the College of Surgeoms to which we owe the voice we have in the elections of members of Council to-day.

These are summarily Mr. Wakley's views on these allimportant subjects. The only proposition I dissent to is that which suggests, "That fellows residing at a certain distance from the College should be allowed to vote by proxy"; but from my personal knowledge of Mr. Wakley's professional and medico-political qualifications I consider him pre-eminently qualified to become a member of Council of the Royal College of Surgeons of England.

I remain, Sir, your obedient servant, JoHN WIBLIN, F.R.C.S. (Exam.)

Southampton, June 17th, 1873 .

\section{THE APPLICATION OF EARTH IN SURGERY.}

To the Editor of THE LANCET.

SrR,-It was my good fortune during the winter to be residing in the same hotels, both at Nice and Rome, with the eminent American surgeon, Dr. Hewson, of Philadelphia, who brought to my notice the advantages attending the use of earth as a dressing in surgical cases. He told me he attributed his great success at the Pennsylvanian General Hospital-a success which has been remarkable since the American war, especially in connexion with cases of amputation-entirely to the use of this agent. The results of its use which have come more or less directly under my own rbservation have been so successful that I venture to send you brief outlines of the cases.

1. A case of epithelioma of the cheek, of twelve years' standing. In December there was an ulcer on the right cheek larger than a half-crown piece, which was being treated with dry-earth applications. In March I saw the case dressed in Rome, as did also Dr. Pantaleoni and other physicians. There were then, instead of the extensive ulcer of three months before, superficial points of ulceration which, had they been collected together, a fourperny-piece would have covered. The patient, a gentleman of sixty-two years of age, was not very sanguine, having had the unfavourable opinions of several distinguished surgeons, but he expressed himself most gratefully for the relief from pain and from the horribly fetid odour, which made life a burden to him before the earth was applied.

2. A physician at Mentone, under Dr. Hughes Bennett's care I believe, sent for Dr. Hewson from Nice to resect his knee-joint, or to amputate his leg. Dr. Hewson found an abscess, thought to be metastatic, in the head of the fibula. He begged to be allowed to try earth dressing before proceeding to an operation. The case did perfectly well, and the joint is apparently as good as ever.

3. The American chaplain in Rome was thrown from his horse, and struck his leg against a rail. The trowsers were not cut, but the tibia, the spine of which was laid bare for several inches, sustained a comminuted fracture, and the tibialis anticus was partly stripped from its attachment. Dr. Hewson put in two or three stitches, and applied earth dressing. The patient had scarcely any pain; there was but little discharge, and the leg rapidly healed. The almost total absence of pain was very remarkable.

4. At Naples a poor woman accosted me in the street, and asked me to cure a large chronic ulcer on the right leg, which extended from the external malleolus to midway between the ankle and knee. I offered her a fer soldi, and told her to go to the hospital. She said she was not begging for money, but to be cured, and as I was an English doctor, I could cure her if I would. Her grandfather had been in the service of an English nobleman, it seemed. I managed to find some light-yellow clay, allowed it to dry, pounded it and sifted it through fine muslin, and applied it to the sore, covering it with ordinary grocer's blue paper, the edges of which I wetted in order to make it adbere to the skin. I told the poor creature to remain at home and rest the ulcerated leg on a chair even when she sat spinning at her door. The next morning I found her waiting for me at the gate of the hotel. She said she was quite free from pain; she had slept all night, a thing she had not done for months before; and with tears in her eyes she thanked me for the relief I had given her. In three weeks the ulcer was almost well. It is right to say I took means to improve the general health.

5. An American gentleman in Rome asked me to prescribe for him, as he had gonorrhoa. The gonorrbcea was very acute, with chordæ and severe pain during micturition. As he bound me to secrecy, I could not borrow a small doubletubed catheter which Dr. Hewson uses in these cases, and was obliged to inject a large quantity of muddy water with an ordinary syringe. The patient was greatly relieved by the iirst application, which was repeated on the two succeeding days, though the discharge and pain had ceased on the second day. The patient had a dose of chloral and an aperient each night.

6. A joung Roman, a friend of the previous patient, came to me complaining of rheumatism. He had had a gleet 
eight months. I injected the urethra with muddy water every other morning for ten days, when the discharge ceased. The rheumatic pains ceased also, supporting, therefore, my friend Dr. Boud's theory of the cause of gonorrbœal rheumatism. This patient took iron and arsenic in small doses, as he was somewhat anæmic.

The freedom from pain, the destruction of all odour from the wound, the diminution of the discharges, and the rapid healing after the application of the earth, were the features common to all these cases which impressed me most.

Dr. Hewson, who will shortly visit England, believes the action of the earth mainly a chemical one, and he covers his dressing with blue paper in order that the chemical rays of light may be admitted to the wound.

I am, Sir, your obedient servant,

Venice, May 17th, 1873. JósePH Groves, B.A., M.B. Lond.

\section{CLINICAL THERMOMETERS AND THEIR DEVIATIONS.}

To the Editor of THE Lavaet.

SiR,-The re-discovery by Mr. Kesteven of the fact that clinical thermometers vary much in the indications which they afford will, it is to be hoped, prevent any one from purchasing one of these instruments unaccompanied by its certificate of verification.

The errors to which all clinical thermometers are liable, and the necessity that exists for their verification at one of the observatories, were pointed out by me in a paper read before the British Medical Association in 1869.

I have several times found, on placing half a dozen of these thermometers in a basin of warm water, that, they have all furnished different readings. Dr. Prior, of Bedford, related some years ago an experiment of comparison which he made with five thermometers, three of them being medical instruments. He plunged them all in water at a temperature of $105^{\circ}$ or $106^{\circ} \mathrm{F}$, and allowed it gradually to cool. The result is given in bis own words: "No two of them precisely corresponded at any time."

What are the principal causes of the errors of clinical thermometers?

1. A difference in the diameter of the bore throughout their length. In consequence of this defect, which seems at present almost unavoidable in their manufacture, the majority of clinical thermometers indicate a temperature sometimes higher, sometimes lower, at other times higher in one part of the scale and lower in another part, than is correct. Here, for example, is a copy of a certificate belonging to one of my clinical thermometers, which not only reads too high, but posseeses a bore of unequal size:"At $85^{\circ}-0.3^{\circ}$; at $90^{\circ}-04^{\circ}$; at $95^{\circ}-0.5^{\circ}$; at $100^{\circ}-0.4^{\circ}$; at $105^{\circ}-0.4^{\circ}, "$

2. A contraction of the glass bulb.-The bulb, having been formed by the aid of heat, undergoes contraction, the fibres of the glass taking some little time to assume their permanent position. Hence it has been usual amongst some makers of meteorological instruments to lay down their thermometers, like their port, for improvement with age. In consequence of this change in the glass, clinical thermometers are apt to read higher as they become older. The alteration in the bulb especially occurs during the year or two immediately succeeding the period of their construction.

What precautions should be taken in order to ensure the possession of trustworthy instruments?

A clinical thermometer unprovided with a certificate of its recent verification at either the $\mathrm{Kew}$ or Greenwich Observatories should never be purchased. The corrections, if any, contained in the certificate, should be applied to each observation that is made.

Those who have employed unverified clinical thermometers should send them to Kew to be verified. A trifling fee is charged by the authorities for the examination of each instrument.

Manufacturers of clinical thermometers should not engrave the scale on the tubes of their thermometers until they have been filled with mercury for at least two years.

It must be remembered, however, that the verification of a two- or three-year old thermometer at an observatory cannot be relied on as a guarantee of the perpetual accuracy of an instrument. The following note is very properly appended to all the certificates issued at $\mathrm{Kew}:$ - "This instrument ought at some future date to be again tested at the melting-point of ice, and, if its reading at that point be found different from that now given, an appropriate correction ought to be applied to all the above points."

I remain, Sir, yours faithfully,

Corneluos B. Fox, M.D., M.R.C.P. Lond. Fellow of the British and Member of the Scottish Scarborough, June 10th, 1873. Meteorological Societies.

\section{IRISH MEDICAL ASSOCIATION.}

To the Editor of THE LANCET.

SIR,-In justice to the Irish Medical Association, a society which for upwards of twenty years has been carrying on its useful operations, I claim of your well-known courtesy and fairness, space in the next issue of your paper to contradict the injurious misstatements of your Dublin correspondent referring to the last meeting of the Society, and which nothing but the most wilful ignorance, or something worse, on his part, could have induced him to publish.

Passing over the ill-natured question as to the annual meeting of the Society as unworthy of notice, I proceed to the statement "that the Council of the Society takes credit to itself for the work done by other societies." This is so vague an accusation that it is difficult to deal with it otherwise than by the simplest but most positive denial of its truth. The Council against which your correspondent makes this gross charge is composed of gentlemen of the highest standing in their profession, among whom are the President and three ex-presidents of the Royal College of Surgeons, and is a sufficient guarantee that any report drawn up with its approval would contain nothing but the most truthful statement of the business transacted by it during its official year, and I defy your correspondent to point out a single statement in the report that cannot be proved by the records of the Society. But your correspondent is guilty of another error in reference to the proposal made by the Society to form among its members some provision for the widows and children of Poor-law and dispensary medical officers. This scheme has now been for two sears under the consideration of the profession, and has been so fully canvassed and discussed by its promoters that the fact of your correspondent mixing up with it the Superannuation Act obtained by the Association two years ago as a provision for the worn-out medical officer (not for his widow), confirms my opinion that he did not take the trouble of being present at the meeting he so incorrectly describes and so unfairly maligns. Dublin, June 16th, 1873. Evant, E. J. Quinan, M.D. Hon. Sec., Irish Medical Association.

* * We have not had time to communicate with our Dublin correspondent on the subject of Dr. Quinan's letter, but feel sure he can give an explanation next week. -Ev. I.

\section{LIFE ASSURANCE COMBINED WITH SICK ALLOWANCE. \\ To the Editor of Ters LANCET.}

SiR,-Several letters have appeared in jour valuable paper lately, urging the establishment of a combined life assurance with sick allowance suitable for members of our profession.

Being one of the directors of the British Provident Life and Guarantee Association, at 96, London-wall, E.C, I brought the subject under the consideration of the board at our last meeting. It was unanimously resolved that the actuary should be instructed to prepare the necessary tables, especially bearing in mind Dr. Woodward's excellent suggestion that the amonnt at death should depend upon the sum drawn out as sick pay.

Our office is a young one, and our subscribed capital is small, but we have no debts, and are doing a good life business. We have an efficient staff, with good central offices, and nothing will be wanted for preliminary expenses beyond a little extra printing, advertising, and postage. 